\title{
Impact of education and training on adults' entrepreneurial mindset: a comparison among MENA countries
}

\section{Mustapha Benouadni*}

\author{
Actuary, Financial Criminality and \\ International Migration Research Laboratory, \\ Hassan II University of Casablanca, \\ Km 8, route d'El Jadida, B.P. 8110, Oasis, Casablanca, Morocco \\ Email: mustapha.benoua@yahoo.com \\ *Corresponding author
}

\section{Najlaa El Cati}

\author{
Entrepreneurship and Organisational Management \\ Research Laboratory, \\ Hassan II University of Casablanca, \\ Km 8, route d'El Jadida, B.P. 8110, Oasis, Casablanca, Morocco \\ Email: najlaa.cati@gmail.com
}

\begin{abstract}
The entrepreneurial mindset is known as a state of mind that pushes people into pursuing their entrepreneurial endeavours (Reed and Stoltz, 2011). The aim of this study is to understand the impact of education and training, as well as culture, on adults' entrepreneurial mindset (self-efficacy, fear of failure and perceived opportunities) in the Middle East and North Africa (MENA) countries. In order to do this, we used a unique global entrepreneurship monitor (GEM) dataset. The sample represents 157,340 adult respondents from 17 MENA countries. We examined our hypotheses via a linear regression and linear hierarchical models. In a large part, our results indicate that training shapes individual entrepreneurial mindset more than education, and the training received later in people's lives have more positive influence than the one received during their schooldays. In addition, national entrepreneurial culture positively influences people's entrepreneurial mindset in the MENA region.
\end{abstract}

Keywords: entrepreneurial mindset; education; training; national conditions; Middle East and North Africa; MENA; global entrepreneurship monitor; GEM.

Reference to this paper should be made as follows: Benouadni, M. and El Cati, N. (2020) 'Impact of education and training on adults' entrepreneurial mindset: a comparison among MENA countries', MENA J. Cross-Cultural Management, Vol. 1, No. 1, pp.80-100.

Biographical notes: Mustapha Benouadni is a $\mathrm{PhD}$ student at the Faculty of Law, Economics and Social Sciences of Casablanca. He graduated with a Bachelor's degree in Finance and Banking, then with a Master's degree in Applied Finance, from Cadi Ayyad University of Marrakesh. He is currently a Corporate Finance Teacher and a Research Projects Supervisor. 
Najlaa El Cati is a PhD student at the Faculty of Law, Economics and Social Sciences of Casablanca. Currently she is a communication skills teacher and a research project supervisor. She has followed a path that promotes economics and entrepreneurship. She graduated with a Bachelor's degree in Economics and Management at ENSET-Mohammedia and a Master's degree in Entrepreneurship and Organizational Management at FSJES-Casablanca. Her academic background has led her to become a training and recruitment consultant. She is an active member of the GEM team. She is also author of several works regarding entrepreneurship.

\section{Introduction}

Over the past two decades, the number of academic and professional institutions offering entrepreneurship programs has increased steadily (Carrier, 2009). This remarkable development is justified through the appreciation of researchers and practitioners of the value that entrepreneurship can bring to a nation. Entrepreneurship education is a powerful opportunity that a country can use to initiate and motivate young students to undertake, to become masters of their own business and to create employment and wealth.

For a long time, entrepreneurship has been considered as a discipline that does not lend itself to teaching. It was only in the 1990s that the role of the education system was recognised as an essential factor in the spread of entrepreneurial culture (Carrier, 2009). The main purpose of the programs dedicated to entrepreneurship education is to introduce young people to entrepreneurship and to provide them with the entrepreneurial mindset and skills essential for their success. In order to build and shape the entrepreneurial mindset, entrepreneurship training is important for better anchoring. This is a crucial step for the student or young entrepreneur to go through in order to put his conative and personal knowledge into practice.

While the number of entrepreneurship education programs has not increased in the Middle East and North Africa (MENA) countries (ICSB, 2019), their effects and impact remain observable. Although, the issue of developing entrepreneurial mindset is rarely addressed in the MENA countries (McMullen and Kier, 2016). The development of the entrepreneurial mindset remains an asset in the Western countries. The challenge at this level is how to promote attitudes and behaviours that can equip individuals, and especially students with the entrepreneurial mindset necessary to confront the difficulties and ambiguities that characterise the business environment.

Currently, most empirical evidence focuses on the impact of education and training programs in the European and American contexts, and ignore the role that education and training programs could play on shaping entrepreneurial mindset in the MENA region. Furthermore, it is a region that is experiencing significant economic, social and cultural development. The education rate tends to be higher among the youngest populations (Fayolle, 2005). However, despite their geographical proximity, countries in the MENA region have different trends and socio-economic and cultural conditions that influence the choice of education and training programs provided, this is an opportunity to overcome these differences.

The purpose of this study is to analyse the impact of education and training programs on the development of people's entrepreneurial mindset (self-efficacy, fear of failure, 
perceived opportunity) in the MENA region. More specifically, the study makes a comparison across 17 MENA countries with regard to their specific cultural and social conditions. We choose the entrepreneurial mindset because it is known that it represents the prior stimulator that pushes people into pursuing their entrepreneurial endeavours. Hence, in this study we want to give an answer to the following question: "How have people's entrepreneurial mindset been shaped by their education and training in MENA countries?". To our knowledge, this is the first study that examines the difference between the effect of training received in school and the effect of training received later in life on shaping people's entrepreneurial mindset.

The paper is structured as follows, we first present a literature review on prior studies on entrepreneurial mindset models and theoretical framework of the impact of education, training and national conditions on entrepreneurial mindset. Then we present the methodology of the research, before reporting results. We conclude by discussing our findings in terms of contributions, limitations, and further research.

\section{Theoretical background and hypotheses}

\subsection{Defining the entrepreneurial mindset}

Fortin (1986) describes entrepreneurship as "a mentality, an attitude that pushes an individual, alone or with others, to launch a new activity". Kanter (1984) defines it as "a spirit, a state of mind associated with an integrative way of approaching problems and decision-making".

There are two visions of entrepreneurship (Léger-Jarniou, 2008). The first approach concerns the result generated by launching a company. The second approach is more extensive, it seeks to understand the entrepreneur's state of mind, his motivations. In fact, we are interested in the second approach. Fostering entrepreneurship is about creating intention before seeking to foster the transition from intention to entrepreneurial action. In order to do this, it is important to equip young people with the attitudes, behaviours and mindset required to develop entrepreneurship. Reed and Stoltz (2011) defined the entrepreneurial mindset as a state of mind that allows the individual to detect the possibilities and opportunities to succeed.

Entrepreneurial mindset is about analysing the world, detecting opportunities and understanding the way people think. Moreover, the entrepreneurial mindset plays the role of a stimulus, as it contributes to the construction and development of the ecosystem, by transforming intentions and ideas into actions (Ferrero and Fioro, 2014). According to the work of McGrath and MacMillan (2000), an entrepreneurial mindset is a term that encompasses three abilities: the ability to perceive, the ability to act immediately and the ability to mobilise resources even under difficult conditions. Therefore, it is a state of mind combining different psychological factors, such as: fear of failure, self-efficacy and perceived opportunity, especially those we are interested in and which we are going to highlight. According to Haynie et al. (2010) the entrepreneurial mindset refers to the ability to anticipate and react promptly and efficiently. In the other hand, several authors have defined the concept from a psychosocial point of view. In fact, they consider entrepreneurial mindset as an attitude and socio-psychological factors (Valerio et al., 2014). 
According to Dhliwayo and Van Vuuren (2007), adopting an entrepreneurial mindset inside an organisation has become an asset and an obligation for the success of the business. Therefore, a business that does not embrace entrepreneurial mindset is more likely to fail than to succeed.

Equipping the individual with an entrepreneurial spirit, helping him or her to promote innovative projects, anticipate change, take risks and manage the business with the least possible flaw. This is a competitive advantage to distinguish oneself in a hostile environment in full mutation (Faltin, 2007). Numerous authors have focused on the examination of the entrepreneurial mindset, with the ultimate goal of understanding it as much as possible. In fact, the work carried out underlines a relationship between this concept and two dimensions: psychological factors related to the individual and cognitive factors (Kuratko, 2002).

\subsection{The relationship between the entrepreneurial mindset and psychological factors}

As we pointed out in the previous section, psychological factors are one of the entrepreneurial mindset dimensions. Psychological capital is characterised by Luthans et al. (2007) as a state of mind. In entrepreneurship, the influence of psychological factors can be investigated in the entire entrepreneurial process, through the influence of education and training (De Hoe and Janssen, 2016). The pursuit of an entrepreneurial career is influenced by the entrepreneur's psychological and cognitive traits (Yamakawa et al., 2013). Psychological factors influence an individual's attitude and behaviour. Because of their importance and the space given to them in the literature (Hayek, 2012), we believe that addressing precisely this dimension of entrepreneurial mindset is important. The factors that we find interesting to analyse are fear of failure, perceived opportunity and self-efficacy.

\subsubsection{Self-efficacy}

Based on Bandura's (1986) socio-cognitive theory, self-efficacy is to be understood as the individual's belief in his or her ability to organise and execute the work plan in order to produce the desired results. Individuals with a sense of self-efficacy tend to set challenging goals; persist in achieving their goals, even under difficult and stressful conditions; and recover promptly from failing, even under disadvantageous conditions. Self-efficacy is a construct indicating that behaviour, knowledge and environment interact in a dynamic way, allowing individuals to form beliefs about their ability to perform specific tasks.

In entrepreneurship, several studies have shown that entrepreneurs have a high degree of self-efficacy (Hayek, 2012). Indeed. By having confidence in their ability to succeed, entrepreneurs become motivated to make all the necessary efforts to ensure the smooth progress of their tasks (Trevelyan, 2011). Entrepreneurs who have a strong perception of their own effectiveness tend to be more stable and successful in dealing with challenges. Therefore, no wonder that entrepreneurs with a high level of self-efficacy succeed in making their businesses reliable and prosperous. Enhancing self-efficiency leads to encouraging the entrepreneurial mindset (Hayek, 2012). 


\subsubsection{Fear of failure}

According to Kilmann et al. (2009), fear and uncertainty are emotions inseparable from the decision-making process that influence an individual's ability to achieve goals and behavioural and cognitive reactions. Conroy (2001) defines the experience of fear of failure as the assessment of threats in a situation with a potential level of failure.

The Enterprise Research Centre is a network of British researchers created in 2013, based at Warwick and Aston Business Schools. Their aim is to identify the determinants that promote the growth of SMEs. Cacciotti and Hayton (2015), address the relationship between the fear of failure and the behavioural and cognitive reactions that individuals may present in an entrepreneurial process. Consequently, they highlight the hypothesis that individuals initially consider fear of failure as a psychological factor preventing entrepreneurship. However, the best way to avoid failure is to reach the goal (Cacciotti and Hayton, 2015), fear can be an additional driver to persevere. This perspective implies that fear is therefore not only a barrier to entrepreneurship, but can also be a source of motivation.

\subsubsection{Perceived opportunities}

Nowadays, opportunity studies are among the most predominant areas of research in the field of entrepreneurship. In fact, many researchers have studied the process of identifying opportunities. Therefore, one of the main purposes was to study how individuals detect them. Perceived opportunity is one of the capacities that can be mobilised by the entrepreneur to identify new opportunities (Drummond et al., 2006; Fairholme and Manber, 2015).

Herron and Sapienza (1992) assert that "entrepreneurial approaches that use psychology and processing theories have many advantages compared to others that do not". The cognitive approach makes it possible to explain the role of the individual's cognitive factors and the process of recognising entrepreneurial opportunities. This perspective makes it possible to better understand not only how the individual acquires, stores, processes and uses information, but also how he thinks, judges, and makes decisions (Mitchell et al., 2004).

\subsection{The role of education and training on shaping the entrepreneurial mindset}

In 1989, Ball gave an emblematic speech at the OECD to promote entrepreneurship at all stages of schooling. As a result, there is almost unanimous policy support for developing entrepreneurship from an early age, mobilising education systems from primary school and even pre-school (Axelsson et al., 2015), to higher education, professional and technical training and adult education (Pilsh and Shimshon, 2007; Young, 2014). Declassified at the state and regional levels, the policy objectives promote educational strategies, systems and practices that are increasingly varied and extensive (Champy-Remoussenard, 2014; European Commission, 2016).

Although they are widespread internationally, Ball's (1989) speech presents important variations in terms of the conceptions of entrepreneurship and in the educational goals involved (Hitty and O'Gorman, 2004). Within the broad field of 'entrepreneurship education', two interpretations of entrepreneurship are generally accepted (Lackéus, 2015). The first refers to the economic world and sees 
entrepreneurship in relation with the creation of business, employment and value (Verstraete and Fayolle, 2005). The purpose here is to develop knowledge about entrepreneurship among young people, or to develop their business creation and management skills; both purposes are generally considered to be in continuity (Breen, 2004). It is then a matter of training future entrepreneurs or developing young people's entrepreneurial mindset (Léger-Jarniou, 2008). Entrepreneurship is thus considered as a learning object in itself (Pepin, 2011).

The second is broader, referring more to human development (Pepin, 2012). The goal here is to develop a culture and values that foster a set of personal, psychological and emotional characteristics in young people, such as autonomy, proactivity, failure management, self-efficacy and a sense of initiative are probably the most consensual (Champy-Remoussenard, 2012). It is therefore a matter of training individuals who are more entrepreneurial in life in general, i.e., developing young people's entrepreneurial mindset (Verzat, 2011). Entrepreneurship is therefore considered as a learning tool (Jones and Iredale, 2010; Pepin, 2011).

According to the studies of Mathisen and Arnulf (2013) there is a beneficial and positive relationship between the entrepreneurial mindset and entrepreneurial activity. The authors conducted a survey among a sample of 242 business school students, and the results indicate that people with an entrepreneurial mindset are more likely to increase their entrepreneurial activities.

Education plays a key role in shaping the individual's identity, personality, attitudes and knowledge. Several authors have shown the strong impact that education has on the development of the entrepreneurial mindset (Gentile et al., 2014). Furthermore, the authors believe that, the personality traits and psychological factors of the individual are important elements of the entrepreneurial mindset. The European Commission (2006) defines education, especially entrepreneurship education, as one of the most powerful paths that contribute directly to increase the levels of economic growth. In fact, the main idea supports the observation that entrepreneurial mindset is teachable and not innate, it is possible to learn how to be an entrepreneur through different specific educational policies and training programs (Erikson, 2002). According to the research studies done by Van der Sluis and Van Praag (2007), there is a positive effect of education and training on entrepreneurial performance. Moreover, the empirical study conducted by Wang and Verzat (2011) shows that the entrepreneurial mindset can be created and shaped through education and training precisely through education and training programs dedicated to entrepreneurship. In fact, entrepreneurship education is seen as a major tool ensuring the development of the attitudes and behaviours required for shaping the entrepreneurial mindset. Due to its importance, many governments have encouraged the creation of entrepreneurship education programs (De Tienne and Chandler, 2004).

The success of any entrepreneurial project requires the presence of certain personal qualities and psychological traits, such as: creativity, autonomy, risk taking, self-efficacity and managing failure (Lazear, 2004; Durkin and Gunn, 2016). Several studies have highlighted the positive influence of entrepreneurship education on the development of specific entrepreneurial mindset factors such as psychological and cognitive factors that are essential to the success of a business and an entrepreneur (De Tienne and Chandler, 2004). The results of the research conducted by Martin et al. (2013) indicate that there is a support for the value of entrepreneurship education and entrepreneurship training programs. 


\subsection{Entrepreneurial mindset, culture}

If experts in the social sciences and humanities were asked to define 'culture', each of them would probably give a different definition compared to their peers. The reason is simple, defining culture is complex because the definition derives from several disciplines (Kroeber and Kluckhohn, 1952). From a biological point of view, 'culture' exists because it allows the members of a group to survive and reproduce (Baumeister and Finkel, 2010).

For many years the definition of Kroeber and Kluckhohn (1952) became the reference for several authors in the field of social psychology. The authors believe that: "Culture consists of both explicit and implicit patterns of ideas derived from history and their realizations among institutions, practices. Cultural models can be considered as outputs of action."

Culture can influence many areas of a given group's life and this influence can be reflected in the individual's behaviour who share it. In fact, distinct behavioural characteristics are attributed to each country because of its culture, and one of the most popular divisions of a country's culture is, the individualism and collectivism (Triandis, 1994) Countries are often characterised as individualistic or collectivist. However, it must be understood that each country is imbued to a different degree with both dimensions. The fact, that individualism advocates personal values justifies the importance the individual gives to his or her own person and family. In addition, the individualists focus on personal achievement and the ability to perform tasks on their own in order to reach their goals (Hofstede, 1980). Also, "people belonging to an individualistic culture see their identity as stable and the social environment as variable. For this reason, they tend to shape the social environment to fit their personality" (Triandis, 2001).

However, being individualistic does not exclude relationships with others, they simply have a different role. People have relationships and belong to various groups that help them achieve their individual goals. However, when a relationship or membership in a group interferes with the achievement of their goals or is too demanding on the individual, the individual will focus on his or her goals rather than to continue to maintain the relationship (Oyserman, 1993).

On the other hand, in collectivist societies, the goals and values of individuals are biased against those of individualistic societies. In fact, "the individuals from a collectivist culture see themselves as interdependent within their group, which provides them with a stable social environment in which to live and work. Their personalities are flexible and their personality traits are not so clear" (Triandis, 2001). In collectivist societies the education of children is based on values of obedience, safety, reliability and conformity. Individuals from collectivist societies are shyer when it comes to integrating a group outside their circle of reference (Triandis, 2001).

The collectivist or individualistic character of a country, impacts the individual's personal decisions. It forges his personality and helps him to position himself in it. In fact, an opened country, which encourages its young people to undertake and sets up policies of training, mentoring and financial support will equip these young people with an entrepreneurial mindset based on reactivity, opportunity detection and creation of wealth (Hamamura, 2012).

A significant number of studies show that there is a link between the individual's values and beliefs on the one hand, and his or her behaviour on the other. According to the psychological traits aggregation approach, for a particular country, the more 
individuals whose values are entrepreneurial, the more entrepreneurial behaviour is found (Shane, 1993).

Therefore, the objective of this study is to compare between adults who were exposed to formal education and training, to find out whether there was any significant difference in entrepreneurial mindset as a result of receiving education and training during and/or after schooldays. In fact, we believe that training would have more positive impact on entrepreneurial mindset than education because of the vocational components of training programs, and training during schooldays would have less positive influence than training received later in someone's life, because the latter is mainly a more qualified program and people would have asked for it. So, in order to conduct this study, our empirical hypotheses are as follows:

Hypothesis 1 Individual entrepreneurial mindset is positively related to the years of education.

Hypothesis 2 Taking any kind of entrepreneurship training enhances the individual entrepreneurial mindset.

Hypothesis 3 Training has more positive impact on individual entrepreneurial mindset than education.

Hypothesis 4 Training received later in someone's life has more positive influence on individual entrepreneurial mindset than training received during his schooldays.

Hypothesis 5 Individuals entrepreneurial mindset are affected by the national conditions of each country.

In other words, hypotheses 1 and 2 describe the impact of education and training received during and after schooldays on the entrepreneurial mindset. Hypothesis 3 is about the gap in impact between education and training on entrepreneurial mindset. Hypothesis 4 defines the difference in impact of training type (received during schooldays or later in life) on entrepreneurial mindset. We can schematise our research model as follows.

Figure 1 Hypothesised effects of education, training and national conditions on entrepreneurial mindset

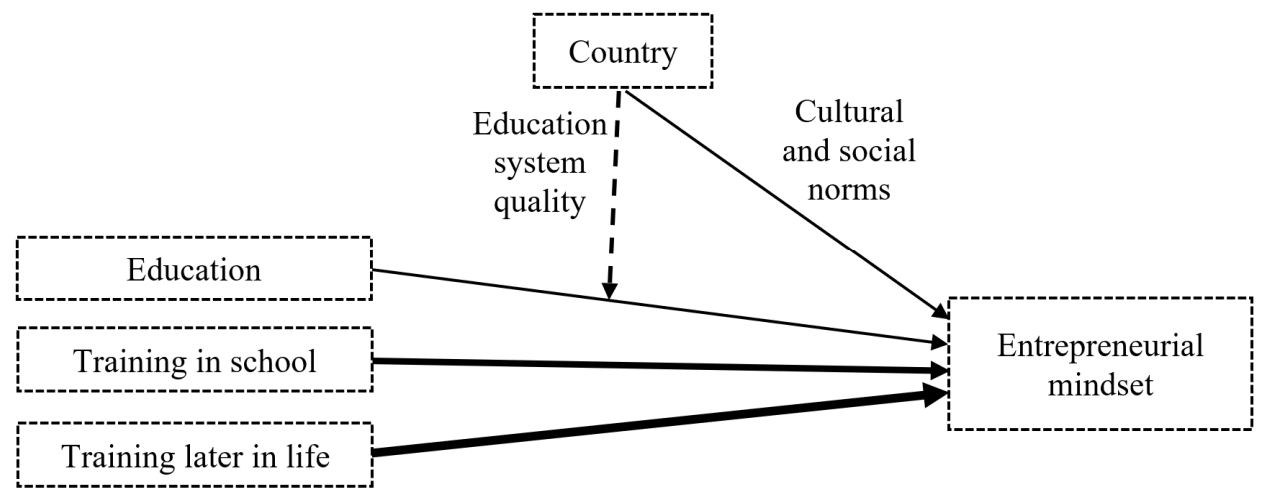




\section{Research design and data}

With the aim of exploring the relationship between MENA adults' education and training to the level of their entrepreneurial mindset, we tried to answer the following questions. To what extent does the level of entrepreneurial mindset vary between MENA adults? How does it change by education and training?

The comparison between numerous countries is mainly difficult because of the data collection of such individual characteristics. Thus, the Global Entrepreneurship Monitor (GEM) platform offers a special database to fulfil this kind of cross-countries studies and therefore fulfil the objectives presented above. The data used in this study were obtained from GEM 2019 dataset. In fact, the unique sample is composed of 17 MENA countries. The reason behind the choice of the MENA region has been encouraged by the lack of studies analysing the real impact of education and training on entrepreneurship in this region. The sample is 157,340 adults aged from 16 to 99 years (see Table 1).

Table 1 Socio-demographic profile of respondents

\begin{tabular}{|c|c|c|c|}
\hline & & $N$ & $\%$ \\
\hline \multirow[t]{2}{*}{ Sex } & Male & 88,696 & 56.38 \\
\hline & Female & 68,610 & 43.62 \\
\hline \multirow[t]{5}{*}{ Age } & $16-24$ & 31,587 & 20.16 \\
\hline & $25-34$ & 43,897 & 28.02 \\
\hline & $35-49$ & 52,114 & 33.27 \\
\hline & $50-64$ & 28,855 & 18.42 \\
\hline & $65-99$ & 190 & 0.12 \\
\hline \multirow[t]{9}{*}{ Education } & 1 & 11,481 & 7.39 \\
\hline & 5 & 17,646 & 11.36 \\
\hline & 9 & 26,374 & 16.97 \\
\hline & 12 & 43,420 & 27.95 \\
\hline & 13 & 17,812 & 11.46 \\
\hline & 15 & 33,503 & 21.56 \\
\hline & 17 & 5,064 & 3.26 \\
\hline & 19 & 58 & 0.04 \\
\hline & 21 & 12 & 0.01 \\
\hline \multirow[t]{4}{*}{ Training } & Only in school & 1,060 & 4.95 \\
\hline & Only later in life & 1,355 & 6.32 \\
\hline & Both & 1,661 & 7.75 \\
\hline & None & 17,358 & 80.98 \\
\hline \multirow[t]{7}{*}{ Occupation } & Full-time employee & 40,679 & 30.03 \\
\hline & Part-time employee & 9,584 & 7.08 \\
\hline & Retired or disabled & 8,788 & 6.49 \\
\hline & Homemaker & 27,763 & 20.50 \\
\hline & Student & 12,895 & 9.52 \\
\hline & Not working & 13,175 & 9.73 \\
\hline & Self-employed & 22,560 & 16.66 \\
\hline
\end{tabular}


The GEM dataset was analysed by the statistical software SPSS (version 25) and the statistical analysis was made by making two-level examination: an individual-level analysis then a cross-countries comparison.

\subsection{Individual-level analysis: impact of education and training on entrepreneurial mindset}

In the first stage of our analysis, we made a linear regression that helped us examine the impact of education and training on entrepreneurial mindset, with a particular focus on the combination of training during schooldays with training received later in life. Here we used a subsample composed of five MENA countries: Egypt, Iran, Kuwait, Qatar and Turkey (see Tables 2 and 3). The reason behind the choice of these five countries has been imposed by the availability of the data for the two training variables and education simultaneously. This subsample is 21,578 adults aged from 18 to 90 years $(2,636$ in Egypt, 6,463 in Iran, 1,973 in Kuwait, 4,116 in Qatar and 6,390 in Turkey).

The GEM database provides measures of adults' entrepreneurial mindset in the shape of self-efficacy, fear of failure and perceived opportunities. Each psychological factor is a dichotomous variable with a 'yes/no' response:

- Self-efficacy: This psychological factor represents the person's self-conviction about his ability to execute effectively actions and then get the intended results (Chen et al., 1998). This psychological factor was measured by asking the respondent: Do you have the knowledge, skill and experience required to start a new business?

- Fear of failure: Also known as risk-taking, it refers to one's disposition to take risks and make risky actions (Rauch and Frese, 2007). This variable was measured by asking the question: Would fear of failure prevent you from starting a new business?

- Perceived opportunities: Kirzner (1979, p.48) defines this psychological factor as the individual "ability to notice without search opportunities that have hitherto been overlooked" by other people. Here, it was measured by asking: In the next six months, will there be good opportunities for starting a new business in the area where you live?

Then, we computed a new variable, mindset "the average entrepreneurial mindset", as an average of the above three psychological factors, to get a unique comparison criterion.

In this database, education was measured by the respondent's highest level of education he has completed. It is measured numerically in years. Training here could be a training during schooldays or received later in life. In addition to the dichotomous measures of the entrepreneurial mindset, training during schooldays was measured by asking the question: Have you ever taken part in training on starting a business at primary or secondary school? and training later in life by asking: Have you ever taken part in training on starting a business after you completed your education in school?

In order to contrast our hypotheses, we have made a linear model introducing our own variables. As mentioned above, we assume that education, training during schooldays and training received later in life have each different impact on the level of the entrepreneurial mindset. For each one of the five countries in our subsample, we estimated the following model: 


$$
\text { mindset }_{i}=\alpha+\beta_{1} e d y_{i}+\beta_{2} \text { ytransc }_{i}+\beta_{3} \text { tranlf }_{i}+\varepsilon_{i}
$$

mindset is the average entrepreneurial mindset, with

$$
\text { mindset }_{i}=\left(\text { suskill }_{i}+\text { nofearfail }_{i}+\text { opport }_{i}\right) / 3 . .
$$

where suskill is the self-efficacy variable, nofearfail is (the reversed of ${ }^{1}$ ) the fear of failure variable and opport is the perceived opportunities variable. Each one of the three above-mentioned variables is a dichotomous variable and coded as 1 for having the psychological factor, 0 if not. So, mindset is a continuous variable that takes as a value 0 , $0.33,0.67$ or 1 . Then, edy is the number of years of education. ytransc is a dichotomous variable and coded as 1 if receiving the training during his schooldays, 0 if not. ytranlf is a dichotomous variable and coded as 1 if receiving the training later in life, 0 if not. Hence, according to our hypotheses, the values of all $\beta$ are positive and we expect that $\beta_{1}<\beta 2<\beta_{3}$.

Since the dependent variable mindset is a continuous variable, we estimated a linear regression. The variables weren't suffering from the multicollinearity problem, as correlations between pairs of variables were moderate (all less than 0.33) and the variance inflation factor (VIF) values were all below 1.13 (see Table 2). The linear regression will help us understand the differences in impacts of education (in years) and training (during school and/or later in life) on the individual entrepreneurial mindset.

Table 2 Means, standard deviations and Pearson correlations among variables in the

\begin{tabular}{|c|c|c|c|c|c|c|c|c|}
\hline & Mean & $\begin{array}{c}\text { Std. } \\
\text { deviation }\end{array}$ & Education & $\begin{array}{c}\text { Training } \\
\text { in } \\
\text { school }\end{array}$ & $\begin{array}{l}\text { Training } \\
\text { later in } \\
\text { life }\end{array}$ & $\begin{array}{c}\text { Self- } \\
\text { efficacy }\end{array}$ & $\begin{array}{l}\text { Fear of } \\
\text { failure } \\
\text { (reversed) }\end{array}$ & $\begin{array}{l}\text { Perceived } \\
\text { opportunities }\end{array}$ \\
\hline Mindset & 0.57 & 0.36 & $0.12 * * *$ & $0.11 * * *$ & $0.14 * * *$ & $0.69^{* * *}$ & $0.61 * * *$ & $0.65 * * *$ \\
\hline Education & 11.82 & 3.28 & & $0.07 * * *$ & $0.11 * * *$ & $0.14 * * *$ & $0.02 * *$ & $0.08 * * *$ \\
\hline $\begin{array}{l}\text { Training in } \\
\text { school }\end{array}$ & 0.11 & 0.32 & & & $0.33^{* * *}$ & $0.13^{* * *}$ & $0.02 * * *$ & $0.06^{* * *}$ \\
\hline $\begin{array}{l}\text { Training in } \\
\text { school }\end{array}$ & 0.13 & 0.33 & & & & $0.17^{* * *}$ & $0.03 * * *$ & $0.06^{* * *}$ \\
\hline Self-efficacy & 0.58 & 0.49 & & & & & $0.15^{* * *}$ & $0.18^{* * *}$ \\
\hline $\begin{array}{l}\text { Fear of } \\
\text { failure } \\
\text { (reversed) }\end{array}$ & 0.67 & 0.47 & & & & & & $0.07 * * *$ \\
\hline $\begin{array}{l}\text { Perceived } \\
\text { opportunities }\end{array}$ & 0.43 & 0.50 & & & & & & \\
\hline
\end{tabular}
subsample

Notes: $* * *$ and $* *$ denote statistical significance at the $1 \%$ and $5 \%$ level, respectively

\subsection{Cross-countries comparison}

In the last stage of our analysis, we performed a comparison across all the 17 MENA countries in our sample (see Table 4). In addition to education, we integrated macro measures of the national education system quality and of the national cultural and social norms, as explanatory variables of the psychological factors, to emphasise the differences between the countries. 
In order to conduct a comparison through all the MENA countries in our sample, we used three hierarchical linear models where mindset is still the dependent variable and $e d y$ is still an independent variable. In the first model, we integrated two macro measures (quality of the national education system $D$, and national cultural and social norms, $I$ ) to emphasise the influence of the national characteristics on the individual entrepreneurial skills in the MENA region.

The GEM database also provides a macro measure of education system quality in each country. It was measured by asking the respondent a five-level Likert scale questions: Teaching in primary and secondary education encourages creativity, selfsufficiency, and personal initiative? Teaching in primary and secondary education provides adequate instruction in market economic principles? Teaching in primary and secondary education provides adequate attention to entrepreneurship and new firm creation? Colleges and universities provide good and adequate preparation for starting up and growing new firms? The level of business and management education provide good and adequate preparation for starting up and growing new firms? and The vocational, professional, and continuing education systems provide good and adequate preparation for starting up and growing new firms? So, the higher score is, the more entrepreneurial national education system is.

The cultural and social norms of every country, in the GEM database, was also measured by asking the respondent a five-level Likert scale questions: The national culture is highly supportive of individual success achieved through own personal efforts? The national culture emphasises self-sufficiency, autonomy, and personal initiative? The national culture encourages entrepreneurial risk-taking? The national culture encourages creativity and innovativeness? and The national culture emphasises the responsibility that the individual (rather than the collective) has in managing his or her own life? So, the higher score is, the more entrepreneurial national culture is.

Then, in the second model, we omitted the macro variables ( $D$ and $I)$ and integrated the main effects of education (edy) in each country. We chose Morocco as the reference in order to make a comparison with each other MENA country in our sample. Finally, in the third model, we integrated the interaction of education with each country. The last model enabled us to examine the differences between each country and the reference country, Morocco, with regard to the effect of education.

\section{Results}

\subsection{Entrepreneurial mindset benefiting from education and training}

To examine effects of education and training upon people's entrepreneurial mindset, we use the subsample of 5 countries (see Table 3). The effects of education and training are ascertained, using a linear regression. Hypotheses 1, 2, 3 and 4, that entrepreneurial mindset is positively affected by education and by training, is tested in this model.

The estimated linear regression of Egypt doesn't violate our hypothesised assumptions. The two training coefficients are only statistically significant at the 0.1 level but education coefficient isn't significant. In fact, training have a positive influence on people's entrepreneurial mindset and receiving training later in someone's life has the greatest positive impact on his entrepreneurial mindset $\left(\beta_{2}=0.044\right.$ and $\left.\beta_{3}=0.0489\right)$. But 
this only supports hypotheses 2 and 4. It appears that both trainings, even combined, have a weak influence on the individual entrepreneurial mindset. Although, adults in this country have the lager entrepreneurial mindset value (constant $=0.652$ ), compared to the other four countries.

In the case of Iran, education has more positive influence on the entrepreneurial mindset than training received later in life which has more positive impact than training received during schooldays $\left(\beta_{1}=0.093, \beta_{2}=0.039\right.$ and $\left.\beta_{3}=0.081\right)$. All these coefficients are significant at the $1 \%$ level. These results are consistent with Hypotheses 1, 2 and 4, but violates Hypothesis 3. For Kuwait, only the coefficients of education and training during schooldays are significant $(p$-value $<1 \%)$. In fact, training in school $\left(\beta_{1}=0.107\right)$ has more positive impact on the individual entrepreneurial mindset than education $\left(\beta_{2}=0.116\right)$. The results for this country are consistent with hypotheses 1,2 and 3 . The regressions of Qatar and Turkey don't violate any of our hypotheses. All the coefficients in the two regressions are statistically significant at the 0.01 level. In fact, we should point out the relative important value of the 'training later in life' coefficient for the two countries ( 0.133 and 0.155 , respectively).

Table 3 Entrepreneurial mindset affected by education and training, in each country

\begin{tabular}{lccccc}
\hline Standardised coefficients ${ }^{(a)}$ & Egypt & Iran & Kuwait & Qatar & Turkey \\
\hline Education & -0.040 & $0.093^{* * *}$ & $0.107^{* * *}$ & $0.045^{* * *}$ & $0.072^{* * *}$ \\
Training during & $0.044^{*}$ & $0.039^{* * *}$ & $0.116^{* * *}$ & $0.077^{* * *}$ & $0.092^{* * *}$ \\
schooldays & & & & & \\
Training later in life & $0.049^{*}$ & $0.081^{* * *}$ & 0.022 & $0.133^{* * *}$ & $0.155^{* * *}$ \\
Constant & $0.652^{* * *}$ & $0.424 * * *$ & $0.356^{* * *}$ & $0.564 * * *$ & $0.426^{* * *}$ \\
$\mathrm{R}^{2}$ & 0.006 & 0.021 & 0.032 & 0.033 & 0.053 \\
$N$ adults & 2636 & 6463 & 1973 & 4116 & 6390 \\
\hline
\end{tabular}

Notes: (a) In order to avoid the scale problem existing between the education variable and the training variables in the estimation, we have to consider the values of the standardised estimated coefficients instead of the unstandardised ones. *** and * denote statistical significance at the $1 \%$ and $10 \%$ level, respectively.

\subsection{Entrepreneurial mindset affected by education system quality and culture}

To examine effects of national context upon entrepreneurial mindset, we use the full sample of 17 countries, but we have to omit training because this was measured in only a few countries, as examined above (see Table 4). First, effects of national conditions are ascertained, using a hierarchical linear model, the first model in Table 4. Hypothesis 5, that entrepreneurial mindset is directly affected by the cultural and social norms of each MENA country, is tested in the first model.

Results of the first model showed that the education coefficient is positive and statistically significant at the $1 \%$ level. Hence, Hypothesis 1 , that education affects entrepreneurial mindset positively, is supported. The results showed also that the cultural and social norms have a significant positive impact $(p$-value $<0.05)$ on the level of the individual entrepreneurial mindset in the MENA region. In fact, people's entrepreneurial mindset is much more influenced by the entrepreneurial culture of their country than by their level of education (respectively, 0.154 and 0.006). The effect of the education system quality isn't statistically significant; which is acceptable since education quality 
wouldn't affect the individual if he didn't receive any kind of education. The interaction between the level of education and the education quality is statistically significant at the $5 \%$ level. Its influence $(0.003)$ is still weak than the influence of the cultural and social norms in the region.

The second model ascertains effects of country differences, instead of ascertaining national conditions. Hypothesis 5 is also tested in this model. The coefficient for education showed that the effect is positive in Morocco (which is the reference country). The second model also showed that countries differ in mindset. More precisely, mindset in Algeria (0.111) is significantly higher than in Morocco. mindset is significantly lower in Yemen $(-0,031)$ than in Morocco. Surprisingly, with a negative coefficient, only Yemen is below the level of Morocco in the whole sample. Compared to the other countries in the MENA region, and beside Yemen and Morocco, countries where people have on average the less entrepreneurial mindset are Kuwait, Iran, Turkey and Tunisia (0.037, 0.052, 0.059 and 0.066 above the level of Morocco, respectively). People who have one average the highest level of entrepreneurial mindset are in Syria, Saudi Arabia, Lebanon and Qatar $(0.221,0.196,0.179$ and 0.158 above the level of our reference, respectively).

The third model ascertains the joint effects of education of adults and country, as an interaction effect. The interaction coefficients are all significant at the $1 \%$ level except those of Syria and Yemen that aren't significant. All the interaction coefficients are positive, which indicates that education in every MENA country has more positive impact on people's entrepreneurial mindset than in Morocco. Countries where education has the lowest influence are Egypt (0.002), Syria (0.003), Pakistan (0.004) and Tunisia (0.005). Those where education has the highest impact are Saudi Arabia (0.016), Kuwait (0.015) and Iran (0.011). The important values of the interaction coefficients of Saudi Arabia and Kuwait would indicate a good quality of the entrepreneurial education programs in these countries compared to the rest of the MENA countries. So, adults in these countries could enhance their weak entrepreneurial mindset by spending more years of education.

Table 4 Entrepreneurial mindset affected by education and national conditions

\begin{tabular}{lccc}
\hline & $\begin{array}{c}\text { Main effects, including } \\
\text { interactions with } \\
\text { national conditions }\end{array}$ & $\begin{array}{c}\text { Main effects, } \\
\text { including } \\
\text { country effects }\end{array}$ & $\begin{array}{c}\text { Interaction } \\
\text { effects with } \\
\text { country }\end{array}$ \\
\hline Constant(a) & 0.201 & $0.415^{* * *}$ & $0.476 \#$ \\
Education & $0.006^{* * *}$ & $0.006^{* * *}$ & $0.000 \#$ \\
$\begin{array}{l}\text { Education system quality } \\
\text { Cultural and social norms }\end{array}$ & -0.057 & --- & $-0.090 \#$ \\
$\begin{array}{l}\text { Education * Education system } \\
\text { quality }\end{array}$ & $0.154^{* *}$ & --- & $0.152 \#$ \\
$\begin{array}{l}\text { Education * Cultural and social } \\
\text { norms }\end{array}$ & $0.003^{* *}$ & --- & --- \\
\hline
\end{tabular}

Notes: (a) Every country in the sample is represented compared to our reference country, Morocco.

*** and $* *$ denote statistical significance at the $1 \%$ and $5 \%$ level, respectively. \# denotes statistical significance was tested in the previous model. 
Table 4 Entrepreneurial mindset affected by education and national conditions (continued)

\begin{tabular}{|c|c|c|c|c|}
\hline & & $\begin{array}{l}\text { Main effects, including } \\
\text { interactions with } \\
\text { national conditions }\end{array}$ & $\begin{array}{l}\text { Main effects, } \\
\text { including } \\
\text { country effects }\end{array}$ & $\begin{array}{l}\text { Interaction } \\
\text { effects with } \\
\text { country }\end{array}$ \\
\hline Algeria & & --- & $0.111 * * *$ & $0.059 \#$ \\
\hline Egypt & & --- & $0.085^{* * *}$ & $0.063 \#$ \\
\hline Iran & & --- & $0.052 * * *$ & $-0.062 \#$ \\
\hline Jordan & & --- & $0.108 * * *$ & $0.022 \#$ \\
\hline KSA & & --- & $0.196^{* * *}$ & $0.020 \#$ \\
\hline Kuwait & & --- & $0.037 * * *$ & $-0.121 \#$ \\
\hline Lebanon & & --- & $0.179 * * *$ & $0.115 \#$ \\
\hline Libya & & --- & $0.094 * * *$ & $-0.002 \#$ \\
\hline Pakistan & & --- & $0.098 * * *$ & $0.050 \#$ \\
\hline Palestine & & --- & $0.077 * * *$ & $-0.005 \#$ \\
\hline Qatar & & --- & $0.158 * * *$ & $0.075 \#$ \\
\hline Syria & & --- & $0.221 * * *$ & $0.195 \#$ \\
\hline Tunisia & & --- & $0.066 * * *$ & $0.025 \#$ \\
\hline Turkey & & --- & $0.059 * * *$ & $-0.020 \#$ \\
\hline UAE & & --- & $0.074 * * *$ & $-0.008 \#$ \\
\hline Yemen & & --- & $-0.031 * * *$ & $-0.034 \#$ \\
\hline \multirow[t]{16}{*}{ Education * country ${ }^{(a)}$} & Algeria & --- & --- & $0.005^{* * *}$ \\
\hline & Egypt & --- & --- & $0.002 * * *$ \\
\hline & Iran & --- & --- & $0.011 * * *$ \\
\hline & Jordan & --- & --- & $0.009 * * *$ \\
\hline & KSA & --- & --- & $0.016^{* * *}$ \\
\hline & Kuwait & --- & --- & $0.015^{* * *}$ \\
\hline & Lebanon & --- & --- & $0.006^{* * *}$ \\
\hline & Libya & --- & --- & $0009^{* * *}$ \\
\hline & Pakistan & --- & --- & $0.004 * * *$ \\
\hline & Palestine & --- & --- & $0.008^{* * *}$ \\
\hline & Qatar & --- & --- & $0.008^{* * *}$ \\
\hline & Syria & --- & --- & 0.003 \\
\hline & Tunisia & --- & --- & $0.005^{* * *}$ \\
\hline & Turkey & --- & --- & $0.008 * * *$ \\
\hline & UAE & --- & --- & $0.008 * * *$ \\
\hline & Yemen & --- & --- & 0,000 \\
\hline
\end{tabular}

Notes: (a) Every country in the sample is represented compared to our reference country, Morocco.

$* * *$ and $* *$ denote statistical significance at the $1 \%$ and $5 \%$ level, respectively.

\# denotes statistical significance was tested in the previous model. 


\section{Discussion, limitations and future research}

The study analyses the impact of education and training programs on the development of adults' entrepreneurial mindset, especially self-efficacy, fear of failure and perceived opportunities, in the MENA region. We compare 17 MENA countries with regard to their specific cultural and social conditions. We choose these psychological factors because it is known that they represent the prior qualities that push people into pursuing their entrepreneurial intentions.

Making an 'average entrepreneurial mindset' variable wouldn't be a good proxy of the various individual psychological factors. It appears that the above-mentioned psychological factors are not homogeneous and the impact of education or training shouldn't be the same on each psychological factor. An average of the three measures wouldn't be so informative. Although, trying to examine the variables that influence the entrepreneurial mindset based on a survey isn't the best way to do so. In fact, the measurements of individual psychological factors are subjective. By answering the survey questions, the respondent makes a self-evaluation of his own abilities and therefore the outputs could be biased and less relevant.

This study could produce more results if other macro socio-economic variables are integrated in the models; e.g. to explain the high value of the entrepreneurial mindset among adults in Egypt, compared to the other four countries in the subsample. Actually, the GEM database provides numerous relevant national measures such as government policies and programs, commercial infrastructure and opportunities to start-up. Beside the effects of education and training on people's entrepreneurial mindset, one could also analyse the potential impact of gender in each country and then examine the gender gap difference through the region. Since the MENA countries are more or less Muslim and patriarchal countries, we believe that women would significantly have weak entrepreneurial mindset that men in this region. In countries where culture is less oldfashioned and institutional conditions are becoming well established (e.g. developing government programs, higher education quality, support for gender equality), the positive influence of education and training could be stronger and the gender gap is believed to be less important.

\section{Conclusions}

The study examines how people's entrepreneurial mindset are shaped by their education and training in MENA countries. This analysis is conducted on a large sample of adults from 17 MENA countries. The sample of 157,340 adult respondents, aged from 16 to 99 years, is obtained from the GEM 2019 dataset.

The individual-level results show that adults' entrepreneurial mindset benefit from education and training. In a large part, training gives individuals higher level of entrepreneurial mindset than their education, and individuals benefit more from the training received later in their lives than the training received during their schooldays. The cross-countries analysis shows that Yemen, Morocco, Kuwait and Iran are the countries where people have on average the less entrepreneurial mindset, compared to the 
other countries in our MENA sample. People with the highest entrepreneurial mindset are in Syria, Saudi Arabia, Lebanon and Qatar. The results also indicate that education in every MENA country has more positive impact on people's entrepreneurial mindset than in Morocco. Countries where education has the lowest influence are Egypt, Syria, Pakistan and Tunisia. Those countries where education has the highest impact on individual entrepreneurial mindset are Saudi Arabia, Kuwait and Iran.

Making a cross-countries analysis through countries that are more or less similar indicates that national characteristics (education quality and cultural and social norms) have significant impacts on people's entrepreneurial mindset. People's entrepreneurial mindset are much more influenced by the cultural and social norms of their country than by their level of education. Moreover, we could emphasise that Saudi Arabia and Kuwait have the best entrepreneurial education programs compared to the rest of the MENA countries in the sample.

\section{Contribution}

Theoretically, this study sheds a light on the gap existing between the impact of training received during schooldays and the impact of training received later in someone's life on entrepreneurial mindset. Prior research has investigated the effect of training on entrepreneurial mindset without point out the significant aspect of its timing. We found out that entrepreneurial mindset is positively affected by training received later in life more than training in schooldays. In fact, we believe that is because training programs promoted as post-school training tend to be more entrepreneurial.

Empirically, by applying a unique sample from GEM (2019), this study contributes to the learning approach of entrepreneurial mindset in developing economies. The research has three major impacts: first, we contribute to examining the impact of type of training, i.e. training in schooldays compared to training later in life, on entrepreneurial mindset for the first time. Second, applying a cross-national dataset enables us to evaluate the effects of different national contexts on individual entrepreneurial mindset. Last but not least, results of this study can be generalised to similar contexts due to the highly representative the sample.

In our sample, $80.98 \%$ of the respondents did not have any kind of entrepreneurial training, in their schooldays or even later in life. Policymakers in MENA countries must extend entrepreneurship education so that more people benefit from it. However, our findings proclaim that education programs in MENA countries are not sufficiently entrepreneurial. Therefore, in order to support entrepreneurship, governments' programs should enhance entrepreneurship education, especially in countries where starting up a business is driven by necessity rather than opportunity. The rates of entrepreneurial activities are higher in developing countries than in developed countries. Because make a living and poverty push people from developing countries to start up a business, while innovation and seeing an opportunity are what motivate people in developed countries (Reynolds et al., 2001; Rosa et al., 2008; Nasiri and Hamelin, 2018). 


\section{Acknowledgements}

Data are collected by the Global Entrepreneurship Monitor (GEM) and responsibility of the statistical analyses remains to the co-authors.

We thank the editor and two anonymous reviewers for constructive comments that have significantly improved the paper. We are grateful to Professor Thomas Schøtt for his excellent research assistance. GEM team provided preferential access to their database for which we are also grateful.

\section{References}

Axelsson, J., Rylander, L., Rignell-Hydbom, A., Jönsson, B.A., Lindh, C.H. and Giwercman, A. (2015) 'Phthalate exposure and reproductive parameters in young men from the general Swedish population', Environ. Int., Vol. 85, No. 1, pp.54-60.

Ball, C. (1989) Towards an 'Enterprising Culture'. A Challenge for Education and Training' (Educational Monograph No. 4), Organisation for Economic Co-operation and Development (OECD)/ Centre for Educational Research and Innovation (CERI), Paris.

Bandura, A. (1986) Social Foundations of Thought and Action: A Social Cognitive Theory, Prentice-Hall, Englewood Cliffs, NJ, 617pp.

Baumeister, R.F. and Finkel, E.J. (2010) Advanced Social Psychology: The State of the Science, Oxford University Press, New York, USA.

Breen, J.P. (2004) 'Enterprise, entrepreneurship and small business: where are the boundaries?', International Journal of Entrepreneurship and Small Business, Vol. 1, Nos. 1-2, pp.21-34.

Cacciotti, G. and Hayton, J.C. (2015) 'Fear and entrepreneurship: a review and research agenda'. International Journal of Management Reviews, Vol. 17, No. 2, pp.165-190.

Carrier, C. (2009) 'L'enseignement de l'entrepreneuriat : au delà des cours magistraux, des études de cas et du plan d'affaires', Revue de l'Entrepreneuriat, Vol. 2, No. 8, pp.17-33.

Champy-Remoussenard, P. (2012) 'L'éducation à l'entrepreneuriat : enjeux, statut, perspectives', Spirale - Revue de Recherches en Éducation, Vol. 50, No. 1, pp.39-51.

Champy-Remoussenard, P. (2014) Innovons et développons l'esprit d'entreprendre, Rapport de recherche, Université Lille 3, Lille, France.

Chen, C., Greene, P. and Crick, A. (1998) 'Does entrepreneurial self-efficacy distinguish entrepreneurs from managers?', Journal of Business Venturing, Vol. 13, No. 4, pp.295-316.

Conroy, D.E. (2001) 'Progress in the development of a multidimensional measure of fear of failure: the Performance Failure Appraisal Inventory (PFAI)'. Anxiety, Stress and Coping, Vol. 14, No. 4, pp.431-452.

De Hoe, R. and Janssen, F. (2016) 'Le capital psychologique permet-il d'apprendre et de rebondir face à un échec entrepreneurial ?', Management International, Vol. 20, No. 2, pp.18-28.

De Tienne, D.R. and Chandler, G.N. (2004) 'Opportunity identification and its role in the entrepreneurial classroom: a pedagogical approach and empirical test', Academy of Management Learning and Education, Vol. 3, No. 3, pp.242-257.

Dhliwayo, S. and Van Vuuren, J.J. (2007) 'The strategic entrepreneurial thinking imperative', Acta Com, Vol. 7, No. 1, pp.123-134.

Drummond S., Paulus M.P. and Tapert S.F. (2006) 'Effects of two nights sleep deprivation and two nights recovery sleep on response inhibition', Journal of sleep research, Vol. 15, No. 3, pp.261-265.

Durkin, C. and Gunn, R. (2016) Social Entrepreneurship: A Skills Approach, 2nd ed., Policy Press, Bristol.

Erikson, T. (2002) 'Entrepreneurial capital: the emerging venture's most important asset and competitive advantage', Journal of Business Venturing, Vol. 17, No. 3, pp.275-290. 
European Commission (2006) 'Entrepreneurship education in Europe: fostering entrepreneurial mindsets through education and learning', Final Proceedings of the Conference on Entrepreneurship Education, Oslo, pp.1-92.

European Commission (2016) Entrepreneurship Education at School in Europe. Eurydice Report. Brussels, Education, Audiovisual and Culture Executive Agency, Belgium.

Fairholme C.P. and Manber, R. (2015) Sleep, Emotions, and Emotion Regulation, pp.45-61, Sleep and Affect, Elsevier, California, USA.

Faltin, G. (2007) The Successful Entrepreneurs Start As An Artist and Composer, German Industry and Commerce, Berlin.

Fayolle, A. (2005) 'Evaluation of entrepreneurship education: behaviour performing or intention increasing?', International Journal of Entrepreneurship and Small Business, Vol. 2, No. 1, pp.89-98.

Ferrero, D. and Fioro, C. (2014) Human Spirits and Entrepreneurship Culture - A New Perspective in the Globalization Era, Austin Macaulay, London.

Fortin, P.A. (1986) Devenez entrepreneur, Presses de l'Université Laval, Québec.

Gentile, M., La Guardia, D., Dal Grande, V., Ottaviano, S. and Allegra, M. (2014) 'An agent based approach to design serious game', International Journal of Serious Games, Vol. 1, No. 2, pp.23-33.

Hamamura, T. (2012) 'Are cultures becoming individualistic? A cross-temporal comparison of individualism-collectivism in the United States and Japan', Personality and Social Psychology Review, Vol. 16, No. 1, pp.3-24.

Hayek, M. (2012) 'Control beliefs and positive psychological capital. Can nascent entrepreneurs discriminate between what can and cannot be controlled?', Journal of Management Research, Vol. 12, No. 1, pp.3-13.

Haynie, J.M., Shepherd, D., Mosakowski, E. and Earley, P.C. (2010) 'A situated metacognitive model of entrepreneurial mindset', Journal of Business Venturing, Vol. 25, No. 2, pp.217-229.

Herron, L. and Sapienza H.J., (1992) 'The entrepreneur and the initiation of new venture launch activities', Entrepreneurship Theory and Practice, Vol. 17, No. 1, pp.49-56.

Hitty, U. and O'Gorman, C. (2004) 'What is 'enterprise education'? An analysis of the objectives and methods of enterprise education programmes in four European countries'. Education and Training, Vol. 46, No. 1, pp.11-23.

Hofstede, G. (1980) 'Culture and organizations', International Studies of Management \& Organization, Vol. 10, No. 4, pp.15-41.

International Council for Small Business (ICSB) (2019) Middle East and North Africa: A New Entrepreneurship Dawn [online] http://icsb2019.com/middle-east-and-north-africa-a-newentrepreneurship-dawn (accessed 24 April 2019).

Jones, B. and Iredale, N. (2010) 'Enterprise education as pedagogy', Education and Training, Vol. 52, No. 1, pp.7-19.

Kanter, J. (1984) Management Information Systems, 3rd ed., Prentice Hall, Upper Saddle River, NJ.

Kilmann, R.H., O'Hara, L.A. and Strauss, J.P. (2009) 'Developing and validating a quantitative measure of organizational courage', Journal of Business and Psychology, Vol. 25, No. 1, pp.15-23.

Kirzner, I.M. (1979) Perception, Opportunity, and Profit: Studies in the Theory of Entrepreneurship, University of Chicago Press, Chicago.

Kroeber, A.L. and Kluckhohn, C. (1952) 'Culture: a critical review of concepts and definitions', Peabody Museum of Archaeology \& Ethnology, Papers, Harvard University, Vol. 47, No. 1, p.viii, p.223.

Kuratko, D.F. (2002) Corporate Entrepreneurship: Entrepreneurial Development within Organisations, Thompson South Western, London. 
Lackéus, M. (2015) Entrepreneurship in Education. What, Why, When, How, 'Entrepreneurship360' Background Paper, Organisation for Economic Co-operation and Development (OECD)/Local Economic and Employment Development (LEED), Paris, France.

Lazear, E.P. (2004) 'Balanced skills and entrepreneurship', American Economic Review, Vol. 94, No. 2, pp.208-211.

Léger-Jarniou, C. (2008) 'Développer la culture entrepreneuriale chez les jeunes', Revue française de gestion, Vol. 5, No. 185, pp.161-174.

Luthans, F., Youssef, C.M. and Avolio, B.J. (2007) Psychological Capital, Oxford University Press, New York.

Martin, B.C., McNally, J.J. and Kay, M.J. (2013) 'Examining the formation of human capital in entrepreneurship: a meta-analysis of entrepreneurship education outcomes', Journal of Business Venturing, Vol. 28, No. 2, pp.211-224.

Mathisen, J-E. and Arnulf, J.K. (2013) 'Competing mindsets in entrepreneurship: the cost of doubt', The International Journal of Management Education, Vol. 11, No. 3, pp.132-141.

McGrath, R.G. and MacMillan, I. (2000) The Entrepreneurial Mindset: Strategies for Continuously Creating Opportunity in An Age of Uncertainty, Harvard Business School Press, USA.

McMullen, J.S. and Kier, A.S. (2016) 'Trapped by the entrepreneurial mindset: opportunity seeking and escalation of commitment in the Mount Everest disaster', Journal of Business Venturing, Vol. 31, No. 6, pp.663-686.

Mitchell, R.K., Busenitz L., Lant T., Mcdougall, P.P., Morse, E.A. and Smith, J.B., (2004) 'The distinctive and inclusive domain of entrepreneurial cognition research', Entrepreneurship Theory and Practice, Vol. 28, No. 6, pp.505-519.

Nasiri, N. and Hamelin, N. (2018) 'Entrepreneurship driven by opportunity and necessity: effects of educations, gender and occupation in MENA', Asian Journal of Business Research, Vol. 8, No. 2, pp.57-71.

Oyserman, D. (1993) 'The lens of personhood: viewing the self and others in a multicultural society', Journal of Personality and Social Psychology, Vol. 65, No. 5, pp.993-1009.

Pepin, M. (2011) 'L'entrepreneuriat en milieu scolaire : de quoi s'agit-il ?', Revue des sciences de l'éducation de McGill, Vol. 46, No. 2, pp.303-326.

Pepin, M. (2012) 'Enterprise education: a Deweyan perspective', Education + Training, Vol. 54, Nos. $8 / 9$, pp.801-812.

Pilsh, T. and Shimshon, B. (2007) Enterprise for All, The Smith Institute, London, UK.

Rauch, A. and Frese, M. (2007) 'Let's put the person back into entrepreneurship research: a meta-analysis of the relationship between business owners' personality characteristics and business creation and success', European Journal of Work and Organisational Psychology, Vol. 16, No. 4, pp.353-385.

Reed, J. and Stoltz, P.G. (2011) Put Your Mindset to Work: The One Asset You Really Need to Win and Keep the Job You Love, Portfolio/Penguin, London.

Reynolds, P.D., Camp, S.M., Bygrave, W.D., Autio, E. and Hay, M. (2001) 'The global entrepreneurship monitor', Executive Report, pp.1-58.

Rosa, P., Kodithuwakku, S.S. and Balunywa, W. (2008) 'Entrepreneurial motivation in developing countries: what does 'necessity' and 'opportunity' entrepreneurship really mean?', Frontiers of Entrepreneurship Research, Vol. 26, No. 20, article 4, pp.1-14.

Shane, S. (1993) 'Cultural influences on national rates of innovation', Journal of Business Venturing, Vol. 8, No. 1, pp.59-73.

Trevelyan, R. (2011) 'Self-efficacy and effort in new venture development', Journal of Management \& Organization, Vol. 17, No. 1, pp.2-16.

Triandis, H.C. (1994) Culture and Social Behavior, McGrawHill, New York.

Triandis, H.C. (2001) 'Individualism-collectivism and personality', Journal of Personality, Vol. 69, No. 6, pp.907-924. 
Valerio, A., Parton, B. and Robb, A. (2014) Entrepreneurship Education and Training Programs Around the World: Dimensions for Success, World Bank Publications, Washington, D.C.

Van der Sluis, J. and Van Praag, M. (2007) Identifying the Difference in Returns to Education for Entrepreneurs and Employees: Identification by Means of Changes in Compulsory Schooling Laws, Working paper, University of Amsterdam, Amsterdam.

Verstraete, T. and Fayolle, A. (2005) 'Paradigmes et entrepreneuriat', Revue de l'Entrepreneuriat, Vol. 4, No. 1, pp.33-48.

Verzat, C. (2011) 'Esprit d'entreprendre, es-tu là ? Mais de quoi parle-t-on ?', Entreprendre \& Innover, Vol. 11, No. 3, pp.7-18.

Wang, Y. and Verzat, C. (2011) 'Generalist or specific studies for engineering entrepreneurs? Comparison of French engineering students' trajectories in two different curricula', Journal of Small Business and Enterprise Development, Vol. 18, No. 2, pp.366-383.

Yamakawa, Y., Peng, M.W. and Deeds, D.L. (2013) 'Rising from the ashes: cognitive determinants of venture growth after entrepreneurial failure', Entrepreneurship Theory and Practice, Vol. 39, No. 2, pp.209-236.

Young, D. (2014) Enterprise for All. The Relevance of Enterprise Education, Department for Business, Innovation \& Skills and Prime Minister's Office, London, UK.

\section{Note}

1 In fact, in order to make this variable a proxy of the respondent's risk-taking, we reversed the measurements of the fear of failure variable. So, a value of 1 refers to that the respondent is not fearing of failure. 